\title{
Análise da desinfecção apical do canal radicular preparado em três diferentes comprimentos de trabalho, utilizando movimento rotatório contínuo ou reciprocante e duas substâncias irrigadoras: estudo in vitro
}

\author{
Analysis of apical root canal disinfection prepared at three different working \\ lengths with either continuous or reciprocating movement systems and two \\ irriganting substances: in vitro study \\ Rodrigo Pimentel LINS ${ }^{*}$ (D), Roberto Paulo Correia de ARAÚJOa (i), \\ Sílvio José Albergaria da SILVA ${ }^{a} \mathbb{D}$, Joice Neves REIS ${ }^{a}(\mathbb{D}$ \\ aUFBA - Universidade Federal da Bahia, Instituto de Ciência da Saúde, Salvador, BA, Brasil
}

\begin{abstract}
Como citar: Lins RP, Araújo RPC, Silva SJA, Reis JN. Análise da desinfecção apical do canal radicular preparado em três diferentes comprimentos de trabalho, utilizando movimento rotatório contínuo ou reciprocante e duas substâncias irrigadoras: estudo in vitro. Rev Odontol UNESP. 2019;48:e20190002. https://doi.org/10.1590/1807-2577.00219
\end{abstract}

\begin{abstract}
Resumo
Introdução: 0 preparo do canal radicular, em especial o terço apical, é fundamental para o sucesso da terapia endodôntica, pois abriga o forame radicular, local que comunica o endodonto com os tecidos perirradiculares. Objetivo: A presente pesquisa avaliou a contaminação do terço apical após a instrumentação de canais radiculares em três comprimentos distintos, através de dois tipos de instrumentação automatizada (rotatória contínua ou reciprocante) e uso de duas substâncias irrigadoras. Material e método: Foram selecionados 66 pré-molares superiores birradiculares, os quais tiveram suas coroas removidas e raízes separadas, totalizando 132 corpos de prova ( $\mathrm{CPs}$ ). Na primeira fase, foram estabelecidos por sorteio seis grupos experimentais divididos de acordo com o comprimento de instrumentação (aquém, além e no forame radicular) e o tipo de instrumentação (rotatória contínua ou reciprocante), tendo como irrigante o hipoclorito de sódio. Na segunda fase, foi repetido o mesmo protocolo, utilizando-se como irrigante o cloreto de sódio. Para ratificar os resultados encontrados, foram criados dois grupos controles: positivo e negativo, cada um com seis CP. Resultado: Não foram encontradas diferenças entre os grupos com instrumentação rotatória contínua ou reciprocante, nos seus diversos comprimentos de instrumentação, respeitando-se o mesmo irrigante. Os grupos irrigados com hipoclorito não apresentaram crescimento bacteriano, enquanto os irrigados com cloreto de sódio permaneceram contaminados após a instrumentação. Conclusão: A ação mecânica dos instrumentos endodônticos sem o uso de substância irrigadora bactericida não promove a descontaminação apical do canal radicular e a escolha do tipo da cinemática dos instrumentos endodônticos (rotatória contínua ou reciprocante) não influencia significativamente a redução de bactérias no interior dos canais radiculares, bem como instrumentações que variam de um milímetro aquém até um milímetro além do forame também não apresentaram diferenças na redução de bactérias nesta pesquisa.
\end{abstract}

Descritores: Instrumentos odontológicos; tratamento do canal radicular; endodontia; ápice dentário.

\begin{abstract}
Introduction: The preparation of the root canal is fundamental for the success of endodontic therapy, especially the apical third, since it contains the root foramen, where the endodontium and the periradicular tissues communicate. Objective: The present study evaluated the contamination of the apical third after the root canal instrumentation in three different lengths, through two types of automated instrumentation (continuous or reciprocating rotating) and two irrigating substances used. Material and method: Sixty-six biradicular maxillary premolars were selected, which had their crowns removed and roots separated,
\end{abstract}


totaling 132 specimens. In the first phase, six experimental groups were divided according to the length of instrumentation (before, beyond and in the radicular foramina) and the type of instrumentation (continuous or reciprocating rotatory) with sodium hypochlorite as irrigator. In the second phase the same protocol was repeated, using sodium chloride as the irrigant. In order to confirm the results, two control groups were created: positive and negative, each with six specimens. Result: For the same irrigant, no differences were found between the groups with continuous or reciprocating rotational instrumentation in their different working lengths. The groups irrigated with hypochlorite showed no bacterial growth, whereas those irrigated with sodium chloride remained contaminated after instrumentation. Conclusion: Mechanical action of endodontic instruments, without bactericidal irrigating substance, does not promote the apical root canal disinfection and the choice of kinematic type of endodontic instruments (continuous or reciprocating rotatory) does not significantly influence the reduction of bacteria within the root canals as well instrumentations ranging from one millimeter before to one millimeter beyond the foramen also did not present differences in the reduction of bacteria in this research.

Descriptors: Dental instruments; root canal therapy; endodontics; tooth apex.

\section{INTRODUÇÃO}

0 terço apical do canal radicular comunica-se com os tecidos periapicais através do forame e pode abrigar um grande número de microrganismos que infectam e promovem inflamação perirradicular persistente. 0 acúmulo de raspas de dentina e restos pulpares na região apical pode obliterar o canal radicular, atuando como barreira mecânica ${ }^{1}$. Essa possibilidade, certamente, interfere na ação das substâncias químicas auxiliares ou da medicação intracanal, até mesmo na região de canal cementário, podendo ser evitada com a realização da manutenção da patência do forame apical².

A limpeza passiva do canal cementário com instrumentos que não ampliam a constrição apical é uma prática possível de ser realizada durante o tratamento endodôntico. Contudo, a ampliação do forame apical com instrumentos mais calibrosos que o instrumento de patência pode contribuir para que um número maior de paredes desta região seja tocado durante a instrumentação e, provavelmente, elas sejam limpas, favorecendo o processo de reparo após o tratamento endodôntico ${ }^{2-5}$. Benatti et al. ${ }^{2}$ verificaram que a ampliação do forame favorece o processo de reparo tecidual ao demonstrar a invaginação dos tecidos periapicais após a realização deste procedimento.

Na atual literatura, não é consensual a eficácia da ampliação foraminal no que diz respeito ao grau de desinfecção do terço apical radicular. 0 insucesso de tratamentos endodônticos pode advir da presença de biofilme maduro formado no periápice radicular, com origem em microrganismos procedentes do sistema de canais radiculares ${ }^{3-6}$.

Acredita-se que a homeostasia dos tecidos da região periapical pode ser alcançada extinguindo ou reduzindo a infecção local em níveis considerados mínimos². São essenciais, entretanto, novas abordagens sobre o tema, baseadas na análise da desinfecção do terço apical radicular através da realização de diversos protocolos de instrumentação em diferentes comprimentos de trabalho.

Considerado o fato de que a patência foraminal auxilia o acesso das substâncias químicas, para alcançarem mais profundamente a região apical, bem como a incerteza de qual cinemática de instrumentação (rotatória contínua ou reciprocante) promove uma maior desinfecção do terço apical, foram estabelecidos protocolos experimentais para este estudo, visando avaliar a influência de diferentes métodos de preparo dos canais radiculares em diferentes comprimentos de instrumentação, com uso de diferentes substâncias irrigadoras, tendo-se em conta a possibilidade de contaminação apical.

Com os diversos sistemas de instrumentação já existentes e o surgimento de tecnologias inovadoras, que visam aprimorar o tratamento endodôntico, são necessários estudos que avaliem essas tecnologias, comprovando ou não a sua eficácia. Esta pesquisa avaliou, in vitro, a ocorrência 
da descontaminação do terço apical do canal radicular através da efetivação de protocolos com instrumentos endodônticos, utilizando, para o movimento rotatório contínuo, as limas Protaper Next, e, para o movimento reciprocante, a lima WaveOne ${ }^{\circledR}$ Gold.

\section{MATERIAL E MÉTODO}

\section{Seleção e Preparo das Amostras}

Foram utilizados 110 pré-molares superiores birradiculares doados pelo Banco de Dentes da União Metropolitana de Educação e Cultura. 0 presente estudo foi aprovado pelo Comitê de Ética em Pesquisa do Instituto das Ciências da Saúde da Universidade Federal da Bahia protocolado sob número 1.852.064, sendo incluídos, na pesquisa em tela, dentes pré-molares superiores humanos, birradiculares (hígidos, restaurados ou cariados), cujas raízes deveriam estar completamente formadas e sem presença de fraturas.

Primeiramente, cada dente foi radiografado no sistema de radiografia digital FONA (Sirona Dental Systems - Schick Technologies Inc., Long Island City, NY, Estados Unidos), com incidência nos sentidos vestibulopalatino e mesiodistal, a fim de confirmar a viabilidade de sua utilização para o estudo, observando-se os seguintes critérios de exclusão: mais de um canal por raiz, canais fusionados, presença de material obturador no canal, medicação intracanal, perfurações e presença de instrumentos fraturados e/ou calcificações. Durante o preparo das amostras, também foram excluídos dentes que não obtiveram a patência do forame, dentes que possuíam diâmetro do forame maior que $0,25 \mathrm{~mm}$, dentes com o forame localizado a mais de três milímetros do vértice apical e dentes com comprimento inferior a $16 \mathrm{~mm}$.

Todos os dentes selecionados pelo pesquisador responsável foram armazenados em solução de timol a $0,1 \%$ e mantidos a $4{ }^{\circ} \mathrm{C}$ até o momento do experimento, quando então foram lavados e colocados em soro fisiológico para a devida reidratação ${ }^{3}$.

Após verificar a compatibilidade com os critérios de inclusão preestabelecidos, foi feita a remoção dos tecidos cariados (quando existentes) com brocas Carbide multilaminada nํㅜ KG ${ }^{\circledR}$ Sorensen (Medical Burs Indústria e Comércio de Produtos Abrasivos Ltda., São Paulo, Brasil). Em seguida, as câmaras pulpares foram acessadas através do uso de pontas de alta rotação, esféricas, diamantadas $\mathrm{n} \times 1014 \mathrm{KG}^{\circledR}$ Sorensen, realizando-se a forma de conveniência com uso de brocas diamantadas de pontas inativas $\mathrm{n} \times 3082 \mathrm{KG}^{\circledR}$ Sorensen. Foi feita uma breve irrigação com um mililitro de cloreto de sódio 0,9\% (Samtec Biotecnologia Ltda., São Paulo, Brasil) e realizado o cateterismo com lima K-File \#10 (Maillefer Instruments Holding Sarl, Ballaigues, Suíça).

Após a localização do forame apical radicular com a lima \#10, foi inserida uma lima K-Flexofile \#25 (Maillefer Instruments Holding Sarl, Ballaigues, Suíça), observando-se se atingiria o forame radicular. Nos casos em que a lima \#25 não atingiu o forame, prosseguiu-se o preparo das amostras. Os forames radiculares foram ajustados no plano axial mediante o uso de limas K-Flexofile \#10, \#15 e \#20 sequencialmente, irrigados com cloreto de sódio ( $\mathrm{NaCl}$ ) 0,9\%. Dessa forma, os forames passaram a ter diâmetros de 0,20 mm. Só então os canais radiculares foram aspirados, preenchidos com solução de EDTA a 17\% (Mln Farmácia de Manipulação Ltda. - Epp, Bahia, Brasil) durante um minuto, e recapitulados com a lima \#10. A seguir, foram irrigados com seis mililitros de solução de hipoclorito de sódio a 2,5\%, NaOCl, (Indústria Anhembi, São Paulo, Brasil), durante 30 segundos, recapitulados com \#10 e mais seis mililitros de $\mathrm{NaCl} 0,9 \%$. Por fim, os canais foram secos com cones de papel absorvente esterilizados.

As coroas foram removidas com o uso de discos diamantados dupla face nํ7016 KG ${ }^{\circledR}$ Sorensen e as raízes separadas para obtenção dos corpos de prova (CPs), isto é, amostras, com, no mínimo $16 \mathrm{~mm}$ de comprimento a partir de seu forame radicular. A demarcação da linha de secção foi 
feita utilizando-se um compasso de ponta seca e grafite, com a ponta seca posicionada no forame radicular e a ponta grafite delimitando onde foi feito o corte em torno da raiz e coroa. Todos os dentes foram numerados e, após a separação das raízes, além da numeração, os CP passaram a ser sinalizados como vestibular (V) ou palatino (P).

\section{Grupos Experimentais}

Foram 12 grupos experimentais divididos de acordo com o tipo de instrumentação (rotatória contínua ou reciprocante), o comprimento de instrumentação (no forame apical, um milímetro aquém ou além do forame apical) e o tipo de substância irrigadora ( $\mathrm{NaCl}$ ou $\mathrm{NaOCl}$ ), além dos grupos controles positivo e negativo. Após verificar compatibilidade com os critérios de inclusão e exclusão, foram selecionados 66 pré-molares superiores humanos birradiculares cujas raízes separadas totalizaram $132 \mathrm{CP}$, distribuídos por sorteio em dez unidades para cada um dos grupos experimentais e seis unidades em cada um dos grupos controles, de acordo com o Quadro 1, observando que cada grupo possuía metade de suas amostras sorteadas em raízes vestibulares e a outra metade sorteadas em raízes palatinas. É importante relatar que, após a distribuição dos corpos de prova, foi feito um novo sorteio para definição dos grupos.

Quadro 1. Distribuição dos grupos experimentais e grupos controles

\begin{tabular}{ccc}
\hline Grupos & $\mathbf{N}^{\circ}$ amostras & Protocolo de instrumentação \\
\hline 1 & 10 & Protaper Next a um milímetro aquém, irrigação com $\mathrm{NaOCl} 2,5 \%$ \\
2 & 10 & Protaper Next no forame, irrigação com $\mathrm{NaOCl} 2,5 \%$ \\
3 & 10 & Protaper Next a um milímetro além, irrigação com $\mathrm{NaOCl} 2,5 \%$ \\
4 & 10 & WaveOne ${ }^{\circledR}$ Gold a um milímetro aquém, irrigação com $\mathrm{NaOCl} 2,5 \%$ \\
5 & 10 & WaveOne ${ }^{\circledR}$ Gold no forame, irrigação com $\mathrm{NaOCl} 2,5 \%$ \\
6 & 10 & WaveOne ${ }^{\circledR}$ Gold a um milímetro além, irrigação com $\mathrm{NaOCl} 2,5 \%$ \\
7 & 10 & Protaper Next a um milímetro aquém, irrigação com $\mathrm{NaCl} 0,9 \%$ \\
8 & 10 & Protaper Next no forame, irrigação com $\mathrm{NaCl} 0,9 \%$ \\
9 & 10 & Protaper Next a um milímetro além, irrigação com $\mathrm{NaCl} 0,9 \%$ \\
10 & 10 & WaveOne ${ }^{\circledR}$ Gold a um milímetro aquém, irrigação com $\mathrm{NaCl} 0,9 \%$ \\
11 & 10 & WaveOne ${ }^{\circledR}$ Gold no forame, irrigação com $\mathrm{NaCl} 0,9 \%$ \\
12 & 10 & WaveOne ${ }^{\circledR}$ Gold a um milímetro além, irrigação com $\mathrm{NaCl} 0,9 \%$ \\
14 & 06 & Controle positivo, sem intervenção e com contaminação \\
\hline
\end{tabular}

Fonte: Dados da pesquisa.

\section{Preparo da Suspensão Bacteriana}

A espécie microbiológica escolhida para a realização desta pesquisa foi a cepa de Enterococcus faecalis (com a identificação: ATCC 29212), cedida pelo Laboratório de Microbiologia da Faculdade de Farmácia da Universidade Federal da Bahia, a partir de uma subcultura cultivada em caldo de infusão (BHI). Em seguida, foi feito preparo desta cepa em solução salina 0,9\%, a fim de se obter uma concentração equivalente à escala 0,5 McFarland e suspensão bacteriana inicial com cerca de 1,5 × $10^{8}$ Unidades Formadoras de Colônias por Mililitro (UFC/mL).

\section{Esterilização dos Corpos de Prova, Instrumentais, Substâncias e Materiais}

Após o preparo das amostras, todos os materiais, instrumentais e substâncias que necessitavam ser esterilizados foram acondicionados em papel grau cirúrgico e filme laminado poliéster/polipropileno, e autoclavados. A esterilização foi realizada a $121{ }^{\circ} \mathrm{C}$ e $1 \mathrm{~atm}$, durante 
20 minutos. Foram feitas desinfecções com álcool $70^{\circ}$ em todas superfícies e materiais não passíveis de esterilização.

Para cada CP a ser instrumentado, foram utilizados exclusivamente: uma pinça, uma gaze, um par de luvas de procedimento, uma ponta de irrigação NaviTip ${ }^{\circledR}$ (25 mm - 30 ga) (Ultradent, South Jordan, Utah, EUA), uma régua endodôntica milimetrada e uma lima \#10, todos devidamente esterilizados, além da lima Easy Clean (Easy Equipamentos Odontológicos, Belo Horizonte, Minas Gerais, Brasil) e as Protaper Next (X1/X2) (Maillefer Instruments Holding Sarl, Ballaigues, Suíça) ou WaveOne ${ }^{\circledR}$ Gold (Primary) (Maillefer Instruments Holding Sarl, Ballaigues, Suíça) já esterilizadas em suas embalagens de fábrica.

\section{Montagem dos Sistemas de Cultura Bacteriana}

Utilizaram-se, para o cultivo das bactérias nos corpos de prova, microplacas de acrílico esterilizadas. Foram inseridos $10 \mu \mathrm{L}$ de caldo de infusão, com uso do pipetador em 10 poços de cada grupo experimental e em seis poços de cada grupo controle. Somente, então, cada CP esterilizado foi removido do papel grau cirúrgico e colocado no seu respectivo poço. Os corpos de prova dos grupos experimentais e do grupo controle positivo foram infectados individualmente com um microlitro da suspensão bacteriana contendo E. faecalis, inserida com uso do pipetador.

Essas microplacas foram tampadas e, para garantir um maior vedamento, foi utilizado filme PVC em torno da placa e, por fim, elas foram colocadas em uma estufa microbiológica a $37^{\circ} \mathrm{C}$ por 96 horas.

\section{Preparo Químico Mecânico dos Grupos Experimentais}

Após 96 horas de incubação, os corpos de prova foram submetidos à instrumentação com limas de único uso. Nos grupos de instrumentação rotatória contínua, as amostras foram instrumentadas com a sequência de limas Protaper Next ${ }^{\circledR} \mathrm{X} 1$ e X2, seguindo-se as recomendações do fabricante.

Para cada CP do Grupo 1, inicialmente foi feita a obtenção do comprimento de patência com a lima \#10 e, a partir de então, foi empregada a lima Protaper Next ${ }^{\circledR}$ X1 (017.04) ao longo da via do canal, em uma ou duas passagens, até se atingir o comprimento de trabalho determinado em um milímetro aquém do forame. Sempre que se encontrava algum tipo de resistência à penetração da lima, ela era removida, limpa com uma gaze esterilizada, e o canal irrigado, realizando-se a manutenção da patência com a lima \#10. Logo após, foi utilizada a lima Protaper Next ${ }^{\circledR} \mathrm{X} 2$ (025.06), exatamente como foi descrito para a lima Protaper Next X1, até que o comprimento de trabalho fosse atingido de forma passiva. Durante o uso de cada lima, o canal radicular foi irrigado com cinco mililitros de $\mathrm{NaOCl} 2,5 \%$, totalizando $10 \mathrm{~mL}$ dessa substância.

No grupo 2, o comprimento de trabalho foi determinado no limite do forame, empregando-se o mesmo protocolo do grupo 1.

Utilizou-se o mesmo protocolo dos grupos anteriores para o Grupo 3, obedecendo-se ao limite de instrumentação em um milímetro além do forame.

Para os grupos 4, 5 e 6, foram utilizados, respectivamente, os mesmos limites de instrumentação dos grupos 1, 2 e 3, tendo como protocolo de instrumentação as limas WaveOne ${ }^{\circledR}$ Gold PRIMARY (025.07), obedecendo-se às recomendações do fabricante, com movimentos suaves e curtos (com dois a três milímetros de amplitude) em direção apical, para avançar passivamente o instrumento, mantendo a trajetória do canal radicular. Ao remover a lima, foi feito o pincelamento das paredes do canal radicular, com o próprio instrumento. A limpeza da lima com gaze esterilizada era sempre feita após cada ampliação, juntamente com a 
manutenção da patência com a lima \#10 e irrigação do canal. A irrigação foi realizada com um total de $10 \mathrm{~mL}$ de $\mathrm{NaOCl} 2,5 \%$.

Os Grupos 7, 8, 9, 10, 11 e 12 seguiram, respectivamente, os mesmos protocolos dos Grupos de 1 a 6, alterando-se apenas a substância irrigadora, que, nesses grupos, foi o cloreto de sódio $0,9 \%$.

Em todos os grupos de estudo, a irrigação foi realizada mediante o uso de seringas descartáveis (Descarpack Descartáveis do Brasil Ltda., São Paulo, Brasil) com pontas NaviTip ${ }^{\circledR}$ esterilizadas e colocadas a quatro milímetros aquém do forame. Para todos os grupos, inclusive os grupos cujo limite apical foi aquém do forame, foi realizada a manutenção da patência com uso de lima \#10.

Concluídas a instrumentação e a irrigação dos corpos de prova, respeitando-se o limite de quatro milímetros do forame, foi aplicado o seguinte protocolo para irrigação final em cada CP, repetido duas vezes: um mililitro de EDTA a 17\%, sob agitação pela Easy Clean ${ }^{\circledR}$ em movimento reciprocante no motor VDW Silver Reciproc ${ }^{\circledR}$, durante 20 segundos, considerado o limite de dois milímetros aquém do comprimento de trabalho. Igualmente à aplicação do EDTA, procedeu-se à irrigação com um mililitro da substância empregada na instrumentação de cada grupo, sob agitação pela Easy Clean ${ }^{\circledR}$, durante 20 segundos, considerado o mesmo limite anterior.

Processada a irrigação final, as amostras foram secas com o auxílio do sugador endodôntico esterilizado Flex Suctor Endodôntico, com ponta de aspiração EndoTips 0.014 (Angelus Ind. de Prod. Odont. SA, Paraná, Brasil), penetrando a dois milímetros do comprimento de trabalho. Em seguida, foram preenchidas com um microlitro $\mathrm{NaCl}$ 0,9\% esterilizado que, em caso de excesso, foi sugado. Por fim, a secagem final de cada CP foi feita com cones de papel Endo Points esterilizados (Endopoints Industrial da Amazônia LTDA., Manacapuru, Amazonas, Brasil), empregados na seguinte sequência: cone de calibre 55 no terço cervical, cone de calibre 40 para o terço médio e cone 20 para o terço apical.

Nenhum tipo de instrumentação foi feito nos grupos controles positivo e negativo. Nesses grupos, cada CP foi preenchido com um microlitro $\mathrm{NaCl}$ 0,9\%, seguindo-se o mesmo protocolo de secagem final descrito anteriormente.

\section{Avaliação da Presença de E. faecalis nos Grupos de Estudo}

Apenas foram utilizados, para análise microbiológica, os cones de calibre 20, referentes aos conteúdos coletados nos terços apicais. Esses cones foram introduzidos em tubos de ensaio com caldo de infusão para avaliação do crescimento microbiano, sendo armazenados em estufa microbiológica e retirados após 12 horas. Como pode ser observado na Figura 1, após o período de armazenamento em estufa, foram encontrados tubos de ensaio com caldos de infusão que estavam turvos e outros translúcidos. 


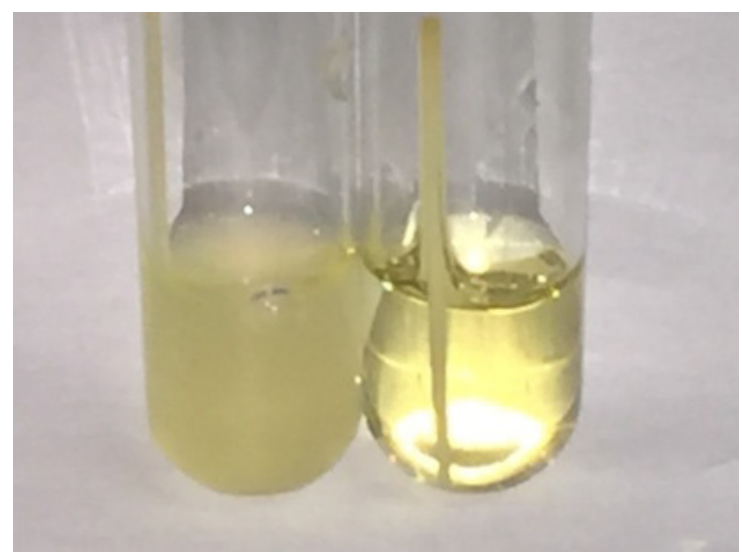

Figura 1. Avaliação da presença de E. faecalis após preparo químico-mecânico. Fonte: Autoria Própria.

Quantificação do número de unidades formadoras de colônia por mililitro (UFC/mL)

Para a avaliação semiquantitativa do número de bactérias, $0,1 \mathrm{~mL}$ de cada diluição foi semeado em duplicata, em placas de Petri com $20 \mathrm{~mL}$ do meio de ágar BHI, para, em seguida, estas serem incubadas a $37{ }^{\circ} \mathrm{C}$, durante 48 horas. É importante salientar que os grupos controles foram submetidos aos mesmos protocolos de avaliação microbiológica dos grupos experimentais. Decorridos 48 horas de armazenamento desse material em estufa microbiológica a $37^{\circ} \mathrm{C}$, dois pesquisadores contaram o número de Unidades Formadoras de Colônias por mililitro, como pode ser visto na Figura 2 (lado esquerdo-amostras com contaminação e lado direito-amostras livres de contaminação).
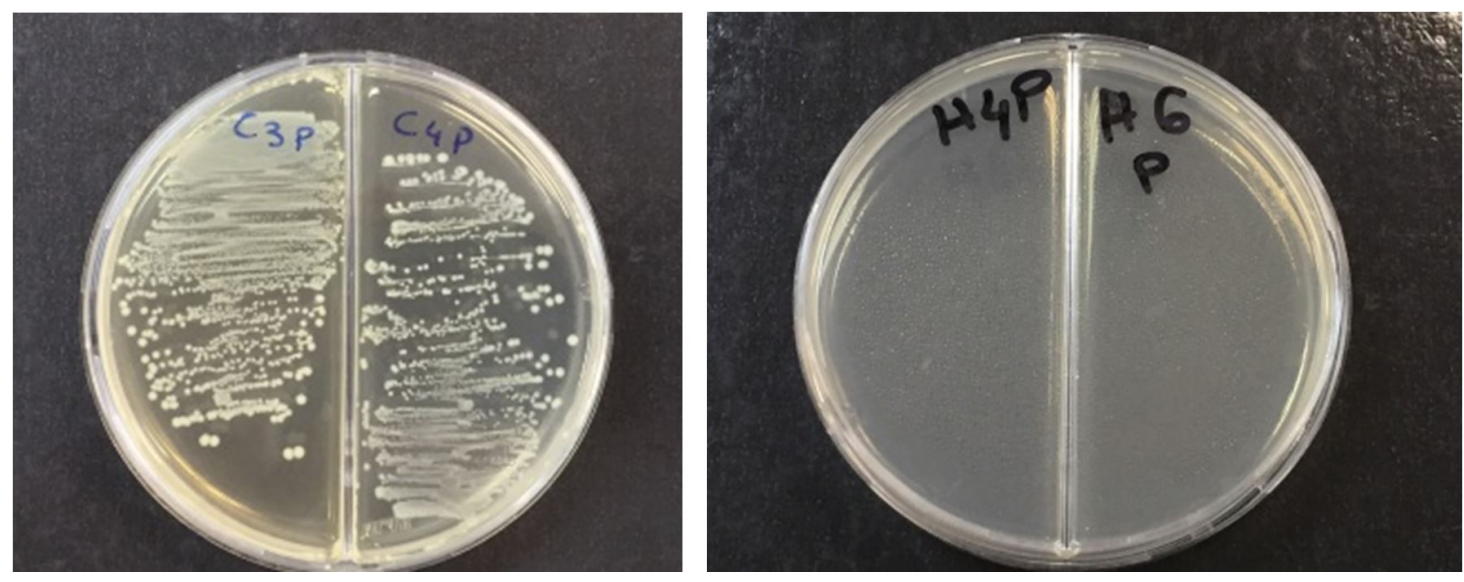

Figura 2. Avaliação semiquantitativa do número de bactérias. Fonte: Autoria Própria.

\section{Avaliação da Pureza das Infecções dos Corpos de Prova}

A partir das colônias formadas nas placas, foram feitos testes de catalase e da biliesculina, e teste com caldo hipercloretado, para descartar a possibilidade de contaminação secundária dos corpos de prova. Através desses testes, pôde-se comprovar que não houve contaminação exógena das amostras, com exceção da terceira amostra do grupo experimental 3.

\section{RESULTADO}

A quantificação do número de unidades formadoras de colônias por mililitro das amostras, nos diversos grupos de estudo, permitiu verificar que, no grupo controle negativo e nos grupos 
irrigados com $\mathrm{NaOCl} 2,5 \%$, não foi encontrado crescimento bacteriano, com exceção de uma amostra do grupo 3, como pode ser observado na Tabela 1. Contudo, todos os CPs irrigados com $\mathrm{NaCl}$ 0,9\% e o grupo controle positivo possuíam mais de $10^{5} \mathrm{UFC} / \mathrm{mL}$.

Tabela 1. Distribuição dos grupos experimentais e grupos controles de acordo com a contagem do número de UFC/mL $(\mathrm{N}=120)$

\begin{tabular}{|c|c|c|c|c|c|c|c|c|c|c|}
\hline $\begin{array}{c}\text { CP } \\
\text { Grupo }\end{array}$ & 1 & 2 & 3 & 4 & 5 & 6 & 7 & 8 & 9 & 10 \\
\hline 1 & 0 & 0 & 0 & 0 & 0 & 0 & 0 & 0 & 0 & 0 \\
\hline 2 & 0 & 0 & 0 & 0 & 0 & 0 & 0 & 0 & 0 & 0 \\
\hline 3 & 0 & 0 & $>10^{5}$ & 0 & 0 & 0 & 0 & 0 & 0 & 0 \\
\hline 4 & 0 & 0 & 0 & 0 & 0 & 0 & 0 & 0 & 0 & 0 \\
\hline 5 & 0 & 0 & 0 & 0 & 0 & 0 & 0 & 0 & 0 & 0 \\
\hline 6 & 0 & 0 & 0 & 0 & 0 & 0 & 0 & 0 & 0 & 0 \\
\hline 7 & $>10^{5}$ & $>10^{5}$ & $>10^{5}$ & $>10^{5}$ & $>10^{5}$ & $>10^{5}$ & $>10^{5}$ & $>10^{5}$ & $>10^{5}$ & $>10^{5}$ \\
\hline 8 & $>10^{5}$ & $>10^{5}$ & $>10^{5}$ & $>10^{5}$ & $>10^{5}$ & $>10^{5}$ & $>10^{5}$ & $>10^{5}$ & $>10^{5}$ & $>10^{5}$ \\
\hline 9 & $>10^{5}$ & $>10^{5}$ & $>10^{5}$ & $>10^{5}$ & $>10^{5}$ & $>10^{5}$ & $>10^{5}$ & $>10^{5}$ & $>10^{5}$ & $>10^{5}$ \\
\hline 10 & $>10^{5}$ & $>10^{5}$ & $>10^{5}$ & $>10^{5}$ & $>10^{5}$ & $>10^{5}$ & $>10^{5}$ & $>10^{5}$ & $>10^{5}$ & $>10^{5}$ \\
\hline 11 & $>10^{5}$ & $>10^{5}$ & $>10^{5}$ & $>10^{5}$ & $>10^{5}$ & $>10^{5}$ & $>10^{5}$ & $>10^{5}$ & $>10^{5}$ & $>10^{5}$ \\
\hline 12 & $>10^{5}$ & $>10^{5}$ & $>10^{5}$ & $>10^{5}$ & $>10^{5}$ & $>10^{5}$ & $>10^{5}$ & $>10^{5}$ & $>10^{5}$ & $>10^{5}$ \\
\hline 13 & $>10^{5}$ & $>10^{5}$ & $>10^{5}$ & $>10^{5}$ & $>10^{5}$ & $>10^{5}$ & & & & \\
\hline 14 & 0 & 0 & 0 & 0 & 0 & 0 & & & & \\
\hline
\end{tabular}

\section{DISCUSSÃO}

O objetivo do tratamento endodôntico é suprimir as populações bacterianas a níveis não detectáveis, através de procedimentos de cultura (indiscutivelmente menor que $\left.10^{4} \mathrm{UFC} / \mathrm{mL}\right)^{1}$. Assim, nesta pesquisa, considerou-se como relevante para designar resultados favoráveis ou desfavoráveis, do ponto de vista técnico, os grupos que apresentaram o número de colônias maior que $10^{4} \mathrm{UFC} / \mathrm{mL}$.

Ao analisar os CPs irrigados com cloreto de sódio, verificamos que todos apresentaram mais de $10^{5} \mathrm{UFC} / \mathrm{mL}$, o que, consequentemente, representa resultados desfavoráveis ao sucesso do tratamento endodôntico. Já a irrigação com hipoclorito de sódio apresentou resultados favoráveis segundo os critérios estabelecidos nesta pesquisa. Ao confrontar os resultados encontrados entre si, ratificamos a importância do uso de substâncias irrigadoras bactericidas, como o hipoclorito de sódio, durante o tratamento endodôntico, pois todos os CPs irrigados com o hipoclorito de sódio evidenciaram resultados negativos para o crescimento das bactérias. Percebeu-se, a partir desses resultados, que apenas a ação mecânica do instrumento endodôntico ou do fluxo da irrigação não eliminou ou reduziu o volume de bactérias a níveis considerados mínimos para obtenção do sucesso na terapia endodôntica, seja em movimentos rotatórios contínuos ou reciprocantes, independentemente do limite estabelecido. Portanto, para obter sucesso no tratamento endodôntico, devem-se utilizar substâncias com capacidade bactericida.

Para a execução de pesquisas envolvendo avaliações microbiológicas, o pesquisador deve estar extremamente atento aos possíveis erros durante a execução do experimento. Portanto, deve ser feito um planejamento criterioso e minucioso, a fim de se evitarem resultados não condizentes com a realidade investigada. Por conta desse raciocínio, esta pesquisa foi totalmente concebida buscando-se evitar qualquer tipo de interferência nos resultados. Pode-se observar que, desde o princípio da execução, houve um preparo prévio das amostras, eliminando-se possíveis interferências que existiriam. Além disso, verifica-se que todos os instrumentais passíveis de esterilização foram esterilizados e foi feita a desinfecção daqueles não passíveis de 
esterilização. É importante observar também que, para cada instrumentação dos corpos de prova, foram utilizados apenas uma vez os materiais (pinça, gaze, limas, luvas, pontas de aspiração, pontas de irrigação, Easy Clean ${ }^{\circledR}$, cones de papel e réguas endodônticas) devidamente esterilizados, manipulados dentro de uma câmara asséptica no Laboratório de Farmacologia da Universidade Federal da Bahia. Além disso, para cada preparo dos CPs, foi utilizada a mesma régua, como é recomendado por Lins et al. ${ }^{7}$, evitando-se, assim, erros de mensuração.

Objetivando maximizar a padronização das amostras, os forames radiculares foram ajustados mediante o uso de limas K-File \#10 e K-Flexofile \#15 e \#20, e, consequentemente, aqueles com menores diâmetros passaram a ter amplitude de $0,20 \mathrm{~mm}$. Também foram excluídas raízes que possuíam forames radiculares maiores que $0,25 \mathrm{~mm}$. Assim, pode-se afirmar que o diâmetro do forame de cada amostra estava padronizado, não interferindo nos resultados encontrados.

0 preparo das amostras conjuntamente com a irrigação, feitos previamente à contaminação dos corpos de prova, favoreceram a remoção de restos necróticos pulpares, remanescentes microbianos e lama dentinária. Caso essas interferências não fossem removidas, possivelmente se tornariam uma barreira para a progressão da contaminação no nível apical, desejada nas amostras, durante a montagem dos sistemas de cultura bacteriana, e, consequentemente, influenciariam os resultados. Portanto, objetivando assegurar a similaridade na contaminação dos corpos de prova, as amostras foram previamente preparadas, como já descrito

A respeito do comprimento de trabalho, Ricucci, Langeland 8 preconizaram que a instrumentação deveria ser realizada respeitando-se o limite do canal dentinário. Adorno et al. ${ }^{6}$ defendem que a instrumentação deve ser realizada aquém do forame, evitando-se, assim, o surgimento de fendas na parede do canal radicular ou rachaduras na região apical. Outros pesquisadores indicam que o forame deve ser instrumentado e ampliado, afirmando trazer melhorias nos resultados do tratamento ${ }^{2,4,5,9-11}$. Contudo, deve-se levar em conta que o uso de limas manuais para ampliação do forame pode influir negativamente, como é relatado por Aragão*, sendo este um dos fatores que influenciaram a ausência de grupos com instrumentação manual na presente pesquisa. Os resultados encontrados para a presente pesquisa estão de acordo com o estudo de Friedman et al. ${ }^{12}$, que não verificaram diferenças significativas quando comparados grupos com e sem ampliação foraminal, pois o número de bactérias presentes após o preparo químico-mecânico dos corpos de prova nos grupos eram semelhantes, levando-se em conta o mesmo irrigante.

Para realização da ampliação foraminal, deve-se levar em consideração o tamanho inicial do forame, pois, como pôde ser visto por Aragão ${ }^{\dagger}$, o alargamento excessivo do forame influi negativamente na regularização dos forames apicais.

Ao avaliar o alargamento foraminal através do uso de microscopia eletrônica de varredura ${ }^{13}$, verificou-se que independentemente da cinemática utilizada (rotatória contínua ou reciprocante), o alargamento foraminal no comprimento de patência ou um milímetro além promove deformação apical. Na pesquisa em tela, o diâmetro inicial do forame nos CP foi de $0,20 \mathrm{~mm}$ após a aplicação de métodos já descritos durante o protocolo experimental e, ao final da instrumentação, podemos afirmar que não houve alargamento sobejo do forame em nenhum dos grupos instrumentados, considerando-se o diâmetro inicial.

0 volume-padrão da substância irrigadora para todos os grupos experimentais foi de dez mililitros, não havendo, assim, diferença entre os diversos grupos. Pesquisas demonstram que certas áreas do canal radicular podem não ser tocadas pelos instrumentos endodônticos e, consequentemente, permanecerem infectadas ${ }^{14,15}$. Por conta disto, foi realizada, neste estudo, a ativação da irrigação.

†Aragão EM de. Avaliação da forma do forame apical após sua patência e ampliação com instrumentos endodônticos [tese]. Universidade Estadual de Campinas: Faculdade de Odontologia de Piracicaba; 2010. 
Segundo alguns autores, através dos diversos tipos de ativação da irrigação, podemos promover a dispersão da substância irrigadora por toda a extensão do sistema de canais radiculares, permitindo que esta alcance os microrganismos não removidos pela insinstrumentação mecânica ${ }^{16-18}$. Portanto, acredita-se que, na atual pesquisa, nos grupos irrigados com o $\mathrm{NaOCl} 2,5 \%$, a ativação da irrigação com uso da Easy Clean ${ }^{\circledR}$ favoreceu a ação bactericida da substância irrigante, possibilitando resultados negativos de cultura e contagem de bactérias, como podem ser vistos na Tabela 1 .

Apesar de não possuir ação bactericida, o cloreto de sódio também foi agitado, com o objetivo de mimetizar o protocolo de irrigação final e favorecer a remoção mecânica das bactérias e de smear layer, não removidos pela instrumentação mecânica, através da geração de uma corrente de fluxo, como preconizado por alguns autores ${ }^{17,18}$. Contudo, com os resultados encontrados na Tabela 1, o fluxo gerado através da agitação da substância irrigadora não foi capaz de eliminar, por si só, as bactérias existentes no interior dos canais radiculares da presente pesquisa.

Para equiparar o grau de instrumentação entre os dois sistemas, foram escolhidas limas com a ponta do instrumento e a conicidade parecidas: Protaper Next X2 (025.06) e WaveOne ${ }^{\circledR}$ Gold Primary (25.07). Contudo, para seguir as recomendações dos fabricantes, foi necessário incluir o uso da lima Protaper Next X1 (017.04) previamente à X2 .

0 canal radicular termina no forame, porém nem sempre está localizado na extremidade apical da raiz, podendo ter a distância de 0,2 a 3,8 $\mathrm{mm}^{19,20}$. A partir desse conhecimento, foram excluídas as unidades dentárias que possuíam o forame cementário localizado a mais de três milímetros do vértice apical, evitando-se, assim, grandes variações da localização do forame referente ao vértice apical.

A espécie bacteriana escolhida para contaminar os CP foi o Enterococcus faecalis, uma vez que a literatura científica demonstra que essa é a espécie mais comumente encontrada nos dentes tratados com a necessidade de reintervenção endodôntica ${ }^{21}$, além de ser consensual o seu uso em estudos in vitro, devido ao rápido crescimento e à fácil manipulação durante o experimento ${ }^{3,20}$.

Sabe-se que toda instrumentação produz debris, umas em maior quantidade outras em menor, mas o importante mesmo é saber que devem ser removidos durante o preparo químico mecânico. Para esta pesquisa, utilizou-se o EDTA 17\% em todos os grupos experimentais, inclusive nos irrigados com $\mathrm{NaCl}$ 0,9\%, para manter semelhança do protocolo de irrigação final, não interferindo nos resultados a serem encontrados.

Como apenas o cone de papel 20 poderia alcançar o forame apical nos grupos instrumentados aquém, ele foi utilizado para avaliação da presença de bactérias ao final do protocolo experimental. Os cones 40 e 55 não foram analisados, pois o maior interesse é avaliar a redução do número de bactérias do terço apical, local que não foi alcançado em sua totalidade por esses cones. Nos grupos em que a instrumentação foi realizada aquém do forame, o cone de papel 20 alcançou o forame, pois eles já estavam calibrados em $0,20 \mathrm{~mm}$.

Os resultados encontrados no grupo controle positivo confirmaram a eficácia do protocolo de infecção dos CPs e a pureza das amostras. Já os resultados do grupo controle negativo demonstraram a eficácia dos processos de esterilização dos CPs, bem como a ausência de infecção secundária durante o período de incubação.

Após a análise do crescimento bacteriano nos tubos de ensaio, foram constatados alguns resultados negativos em diversos grupos de estudo desta pesquisa. Mesmo assim, foi feita a semeadura desses exemplares em placas de Petri com meio ágar, para comprovar os resultados encontrados, diferentemente de outra pesquisa ${ }^{3}$, que analisou apenas os grupos que obtiveram turvação do seu meio de cultura. Para esta pesquisa, foi confirmada a ausência de bactérias nos grupos irrigados com hipoclorito de sódio, mas, nos grupos irrigados com cloreto de sódio, as amostras, aparentemente negativas, possuíam, na realidade, um número de unidades formadoras de colônias por mililitro acima de cem mil. 
Assim como no estudo de Ferrer-Luque et al. ${ }^{3}$, para manter e ratificar os resultados da presente pesquisa, foram feitas as avaliações da pureza das infecções dos corpos de prova, nas quais se pôde perceber que não houve contaminação secundária entre as amostras ou delas com o meio ambiente. Foi observada uma exceção desse fato, pois a terceira amostra do grupo 3 demonstrou estar infectada por outro tipo de bactéria e, portanto, não pôde ser incluída na análise final dos resultados.

Moreira et al. ${ }^{22}$ concluíram, em seus estudos, que o desbridamento foraminal não apresentou diferença significativa quanto à redução das colônias de E. faecalis, quando comparado ao do grupo em que não se realizou o desbridamento. Mesmo assim, durante o preparo dos grupos experimentais instrumentados desta pesquisa, foi realizada a manutenção da patência, como é indicado por Gulabivala et al. ${ }^{17}$, evitando-se o acúmulo de semear layer e facilitando o fluxo e o alcance da substância irrigadora ao forame, mas não desgastando suas paredes.

0 insucesso de tratamentos endodônticos pode advir da presença de biofilme maduro, formado no periápice radicular, com origem em microrganismos procedentes do sistema de canais radiculares. Recentemente, várias pesquisas vêm apresentando resultados favoráveis a procedimentos que promovem a ampliação do forame radicular ${ }^{4,9,10}$. Segundo alguns autores ${ }^{23}$, preparos apicais mais amplos, independentemente do sistema de instrumentação empregado, parecem estar positivamente associados à maior desinfecção dos canais. Entretanto, na presente pesquisa, não foi constatada uma desinfecção significativa do terço apical, mesmo nos casos de sobreinstrumentação e consequente ampliação foraminal, pois os resultados demonstraram-se semelhantes para a redução do número de bactérias, independentemente do comprimento de trabalho utilizado, levando em consideração um mesmo irrigante.

Assim como Ferrer-Luque ${ }^{3}$, na presente pesquisa, constatou-se que a cinemática da lima (rotatório contínuo ou reciprocante) não interferiu de forma significativa na redução do número de bactérias existentes, pois, ao compararmos grupos instrumentados num mesmo comprimento de trabalho e com a mesma substância irrigadora, foram encontrados resultados semelhantes.

Levando-se em consideração os resultados desta pesquisa, em que não foram encontradas diferenças significativas entre os grupos instrumentados aquém, além ou no forame radicular, e baseado na literatura existente, na qual alguns autores defendem a instrumentação aquém do forame $e^{2,5,8}$ e outros defendem a ampliação do forame $e^{4,9}$, constata-se a necessidade da elaboração de mais pesquisas sobre este tema para estabelecer qual protocolo trará melhores resultados ou se realmente não há diferenças significativas na redução de bactérias entre esses diferentes protocolos de instrumentação.

\section{CONCLUSÃO}

Diante dos resultados obtidos no presente estudo, conclui-se que no momento imediato após o preparo químico-mecânico dos canais radiculares:

1 -A instrumentação do forame ou a sua ampliação não promoveram melhores resultados quando comparadas à instrumentação a um milímetro do forame com manutenção da patência, independentemente do tipo de movimento de instrumentação (rotatório contínuo ou reciprocante) para o mesmo tipo de substância irrigadora.

2 -A ação de instrumentos com movimento rotatório contínuo não apresentou resultados melhores quando comparada à ação em movimento reciprocante. Os dois tipos de movimento apresentaram resultados semelhantes quanto à presença de unidades formadoras de colônia por mililitro, após os protocolos experimentais, considerando-se a mesma substância irrigadora. 
3 -A ação mecânica dos instrumentos endodônticos sem o uso de substância irrigadora com capacidade bactericida é ineficaz no processo de descontaminação apical de canal radicular.

\section{REFERÊNCIAS}

1. Siqueira JF Jr, Rôças IN. Clinical implications and microbiology of bacterial persistence after treatment procedures. J Endod. 2008 Nov;34(11):1291-301.e3. http://dx.doi.org/10.1016/j.joen.2008.07.028. PMid:18928835.

2. Benatti O, Valdrighi G, Biral RR, Pupo J. A histological study of the effect of diameter enlargement of the apical portion of the root canal. J Endod. 1985 Oct;11(10):428-34. http://dx.doi.org/10.1016/S00992399(85)80080-7. PMid:3865987.

3. Ferrer-Luque CM, Bejarano I, Ruiz-Linares H, Baca P. Reduction in Enteroccocus faecalis counts - a comparison between rotary and reciprocating systems. Int Endod J. 2014 Apr;47(4):380-6. http://dx.doi.org/10.1111/iej.12158. PMid:23980811.

4. Brunson M, Heilborn C, Johnson DJ, Cohenca N. Effect of apical preparation size and preparation taper on irrigant volume delivered by using negative pressure irrigation system. J Endod. 2010 Apr;36(4):721-4. http://dx.doi.org/10.1016/j.joen.2009.11.028. PMid:20307751.

5. Souza Filho FJ, Benatti O, Almeida OP. Influence of the enlargement of the apical foramen in periapical repair of contaminated teeth of dog. Oral Surg Oral Med Oral Pathol. 1987 Oct;64(4):480-4. http://dx.doi.org/10.1016/0030-4220(87)90157-5. PMid:3477772.

6. Adorno CG, Yoshioka T, Suda H. The effect of working length and root canal preparation technique on crack development in the apical root canal wall. Int Endod J. 2010 Apr;43(4):321-7. http://dx.doi.org/10.1111/j.1365-2591.2010.01684.x. PMid:20487452.

7. Lins RP, Menezes LVP, Araújo RPC, Silva SJA, Mendes CMC. Exatidão e precisão das réguas milimetradas utilizadas durante procedimentos endodônticos. Rev Ciênc Méd Biol. 2016 Fev;14(3):286-92. http://dx.doi.org/10.9771/cmbio.v14i3.14988.

8. Ricucci D, Langeland K. Apical limit of root canal instrumentation and obturation, part 2. A histological study. Int Endod J. 1998 Nov;31(6):394-409. http://dx.doi.org/10.1046/j.1365-2591.1998.00183.x. PMid:15551607.

9. Gurgel-Filho ED, Castelo-Branco YN, Maniglia-Ferreira C, Souza-Filho FJ, Coutinho-Filho T. Avaliação in vivo da dor pós-operatória em dentes vitais após o alargamento do forame apical. RFO UPF. 2010 Maio-Ago;15(2):145-9.

10. Silva EJ, Menaged K, Ajuz N, Monteiro MR, Coutinho-Filho TS. Postoperative pain after foraminal enlargement in anterior teeth with necrosis and apical periodontitis: a prospective and randomized clinical trial. J Endod. 2013 Feb;39(2):173-6. http://dx.doi.org/10.1016/j.joen.2012.11.013. PMid:23321226.

11. Brandão PM, Figueiredo JAP, Morgental RD, Scarparo RK, Hartmann RC, Waltrick SBG, et al. Influence of foraminal enlargement on the healing of periapical lesions in rat molars. Clin Oral Investig. 2019 Apr;23(4):1985-91. http://dx.doi.org/10.1007/s00784-018-2628-2. PMid:30386994.

12. Friedman S, Abitbol S, Lawrence HP. Treatment outcome in endodontics: the Toronto study. Phase 1 : initial treatment. J Endod. 2003 Dec;29(12):787-93. http://dx.doi.org/10.1097/00004770200312000-00001. PMid:14686806.

13. Silva Santos MA, Portela FMSF, Coelho MS, Fontana CE, De Martin AS. Foraminal deformation after foraminal enlargement with rotary and reciprocating kinematics: a scanning electronic microscopy study. J Endod. 2018 Jan;44(1):145-8. http://dx.doi.org/10.1016/j.joen.2017.08.013. PMid:29033083. 
14. Mauger MJ, Schindler WG, Walker WA 3rd. An evaluation of canal morphology at different levels of root resection in mandibular incisors. J Endod. 1998 Sept;24(9):607-9. http://dx.doi.org/10.1016/S0099-2399(98)80120-9. PMid:9922750.

15. Wu MK, R'oris A, Barkis D, Wesselink PR. Prevalence and extent of long oval canals in the apical third. Oral Surg Oral Med Oral Pathol Oral Radiol Endod. 2000 Jun;89(6):739-43. http://dx.doi.org/10.1067/moe.2000.106344. PMid:10846130.

16. Bortoluzzi EA, Carlon D Jr, Meghil MM, El-Awady AR, Niu L, Bergeron BE, et al. Efficacy of 3D conforming nickel titanium rotary instruments in eliminating canal wall bacteria from oval-shaped root canals. J Dent. 2015 May;43(5):597-604. http://dx.doi.org/10.1016/j.jdent.2015.01.001. PMid:25593001.

17. Gulabivala K, Ng YL, Gilbertson H, Eames I. The fluid mechanics of root canal irrigation. Physiol Meas. 2010 Dec;31(12):R49-84. http://dx.doi.org/10.1088/0967-3334/31/12/R01. PMid:21071831.

18. Kato AS, Cunha RS, Silveira Bueno CE, Pelegrine RA, Fontana CE, Martin AS. Investigation of the efficacy of passive ultrasonic irrigation versus irrigation with reciprocating activation: An environmental scanning electron microscopic study. J Endod. 2016;42(4):659-63.

19. Gutierrez JH, Aguayo P. Apical foraminal openings in human teeth. Number and location. Oral Surg Oral Med Oral Pathol Oral Radiol Endod. 1995 June;79(6):769-77. http://dx.doi.org/10.1016/S10792104(05)80315-4. PMid:7621038.

20. Mizutani T, Ohno N, Nakamura H. Anatomical study of the root apex in the maxillary anterior teeth. J Endod. 1992 July;18(7):344-7. http://dx.doi.org/10.1016/S0099-2399(06)80486-3. PMid:1402598.

21. Siqueira JF Jr, Rôças IN. Polymerase chain reaction-based analysis of microorganisms associated with failed endodontic treatment. Oral Surg Oral Med Oral Pathol Oral Radiol Endod. 2004 Jan;97(1):85-94. http://dx.doi.org/10.1016/S1079-2104(03)00353-6. PMid:14716262.

22. Moreira ALB, Gadê Neto CR, Dametto FR, Sant'Anna GR, Carvalho RA. Eficácia das manobras de desbridamento no preparo químico-mecânico quanto à desinfecção no terço apical em molares humanos. Rev Odontol UNESP. 2016 Fev;45(1):27-32. http://dx.doi.org/10.1590/1807-2577.05015.

23. Plotino G, Tocci L, Testarelli L, Gambarini G. Foraminal deformation after foraminal enlargement with rotary and reciprocating kinematics: a scanning electronic microscopy study. J Oral Res. 2014 Jul;5(2):4.

\section{CONFLITOS DE INTERESSE}

Os autores declaram não haver conflitos de interesse.

\section{*AUTOR PARA CORRESPONDÊNCIA}

Rodrigo Pimentel Lins, Alameda Horto Bela Vista, 808, Horto Bela Vista, Condomínio Reserva das Plantas, Edifício Bromélia, Apartamento 403, 41098-030 Salvador - BA, Brasil, e-mail: rplins@live.com

Recebido: Janeiro 11, 2019

Aprovado: Agosto 5, 2019 